\title{
LA-UR- $98-4218$
}

Prediction of Heat of Melting and Heat Capacity

of Inorganic Liquids by the Method of Group Contributions

Joel D. Williams

Los Alamos National Laboratory

James M. Eakman

University of Nebraska

Mark M. Montoya

New Mexico State University

Prepared for presentation at the 1997 Annual Meeting,

Los Angeles, CA, November 16-21

Thermodynamics and Phase Behavior

November 17, 1997

AICHE shall not be responsible for statements or opinions contained in papers or printed in its publications. 


\section{DISCLAIMER}

This report was prepared as an account of work sponsored by an agency of the United States Government. Neither the United States Government nor any agency thereof, nor any of their employees, makes any warranty, express or implied, or assumes any legal liability or responsibility for the accuracy, completeness, or usefulness of any information, apparatus, product, or process disclosed, or represents that its use would not infringe privately owned rights. Reference herein to any specific commercial product, process, or service by trade name, trademark, manufacturer, or otherwise does not necessarily constitute or imply its endorsement, recommendation, or favoring by the United States Government or any agency thereof. The views and opinions of authors expressed herein do not necessarily state or reflect those of the United States Government or any agency thereof. 


\section{Introduction}

One of the unfulfilled needs in the field of chemical engineering is the ability to estimate many thermodynamic properties of compounds. This need gives rise to overly conservative equipment design and the associated increase in cost for the fabrication, installation and operation of this equipment. Many of these properties such as heat capacities for liquids and enthalpy of fusion have been studied and, in some cases, estimated for some pure organic compounds.

However, there are wide variety of inorganic compounds which are becoming more important in all aspects of the chemical industry. Among these, salts are being used to a greater extent than ever before. Many of these materials must be used in the liquid (or molten) state as either reagents or solvents within which other chemical reactions may occur. Many more complex salts and salt/oxide combinations are being considered for the immobilization and storage or disposal of hazardous or radioactive wastes. There is very little information concerning such fundamental properties as heat of fusion and heat capacities for many of these inorganic materials.

This work will focus on the use of elements or simple functional groups to estimate some of these fundamental thermodynamic properties for a variety of inorganic compounds. The major emphasis will be on properties for which some ancillary information may be easily measured, but which may be very difficult to measure directly. An example of such a property is the heat of fusion (or melting). The melting temperature for most pure 
materials is relatively easy to measure. However, the actual amount of energy required to liquefy, or conversely, the amount of energy which must be removed to solidify those same materials has not been measured. Similarly, important properties such as heat capacities of liquids are unavailable for many compounds. Such information is essential in the chemical industry and are paramount for chemical engineers if they are to design, build and operate plants and facilities in an economical and efficient manner.

Thermodynamic properties may be estimated by the method of group contributions represented in the general form:

$\mathrm{P}=\sum$ Contribution of cationic groups $+\sum$ Contribution of anionic groups

$+\sum$ Contribution of functional groups

Cationic groups would include most cations, usually represented as metallic elements rather than functional groups. Anionic groups would include those generally thought of as being constituents of "salts", such as halogens, oxides or non-metallic functional groups. These may be elements such as chlorine, bromine, etc., or functional groups such as carbonate, nitrate and sulfate which are important and are included in the present work.

\section{PREDICTION OF THE ENTROPY OF MELTING}

In order to make an initial estimate of equipment size and heat duties, an estimate of the heat required to melt compounds is necessary. The thermodynamic definition of heat of melting is: 


$$
\Delta \mathrm{H}_{\text {fusion }}=\mathrm{T}_{\mathrm{f}} \Delta \mathrm{S}_{\text {fusion }}
$$

where $\Delta \mathrm{H}$ is the enthalpy of melting (or fusion), $\mathrm{T}$ is the absolute temperature at which the phase change occurs and $\Delta S$ is the entropy of melting (or fusion). Reid (1987) points out that the enthalpy depends primarily upon intermolecular forces while the entropy is a function of the molecular symmetry. This implies that the entropy will be larger for compounds in which the molecules can assume many different orientations in the liquid phase relative to the solid. This further implies that the melting entropy will be smaller for compounds which have spherical, rigid molecules since they have fewer different orientations in the liquid when compared to the solid phase.

Reid (1987) states that attempts to obtain general correlations for the enthalpy of melting have been unsuccessful. One of the reasons for this lack of success is the fact that the enthalpy change is in part dependent on the crystalline form of the solid phase. The Clausius-Clapeyron equation can be used to estimate the heat of melting. However, as shown in the equation below, data on the variation of melting point with pressure is required and this information is seldom available.

$$
\mathrm{dP}_{\mathrm{sat}} / \mathrm{dT}=\Delta \mathrm{H}_{\mathrm{m}} / \mathrm{T} \Delta \mathrm{V}_{\mathrm{m}}
$$

rigidity of the crystalline form, good agreement between calculated and experimental values were shown for eight metallic elements.

Bondi (1967) correlated the entropy of melting of molecular crystals to molecular structure. One of the departures from conventional definitions suggested by Bondi is that the melting process actually begins with any phase transitions in the solid. This means that the entropy of melting consists of the summation of all solid state phase transitions and the more conventionally recognized phase transition from solid to liquid. This implies that phenomenologically, the entropy of melting consists of two distinct components: that due to the volume increase and the entropy of melting at constant volume. The first portion, 
the change in entropy associated with an increase in volume, is what is generally reported as the entropy of melting. By using a very general model for melting, such as that suggested by Hirschfelder, Stevenson and Eyring (HSE) (1937), Bondi expresses the entropy of melting by the following relationship:

$$
\Delta \mathrm{S}_{\mathrm{m}}=\Delta \mathrm{S}_{\mathrm{p}}+\Delta \mathrm{S}_{\mathrm{m}(\mathrm{rot})}
$$

where $\Delta S_{p}$ is the entropy contribution due to positional disordering within the crystal, and

$$
\Delta \mathrm{S}_{\mathrm{m}(\text { rot })}=\mathrm{S}_{\mathrm{r}}-\mathrm{S}_{\mathrm{tor}}
$$

where $S_{r}$ is the appropriate rotational contribution and $S_{\text {tor }}$ is the entropy contributions due to torsional oscillation in the crystal lattice. Due to the difficulty of measuring torsional oscillations and the scarcity of data, Bondi concentrated on the rotational contribution only. Using the HSE model, $\Delta S_{p}$ can be estimated by $R$, the gas constant. This implies that for compounds with with no rotational contribution, the entropy of melting should be approximated by the gas constant and have a value of approximately $8.314 \mathrm{~J} / \mathrm{mole}^{\circ} \mathrm{K}$.

Denbigh (1971) states that in the case of substances consisting of fairly compact molecules, the value of the entropy of fusion is typically between 8 and $16 \mathrm{~J} / \mathrm{mole}^{\circ} \mathrm{K}$. However this value may be as high as $40 \mathrm{~J} / \mathrm{mole}^{\circ} \mathrm{K}$ and, in the case of elongated molecules such as hydrocarbons, may be $120 \mathrm{~J} /$ mole $^{\circ} \mathrm{K}$ or more. This also implies a relationship between shape and melting entropy.

A more recent correlation based on configurational considerations has been proposed by Dannenfelser (1996). A large number of organic compounds, encompassing a variety of shapes was used in developing the method. The general form of the equation for entropy of melting used by Dannenfelser is:

$$
\Delta \mathrm{S}_{\mathrm{m}}{ }^{\text {tot }}=\Delta \mathrm{S}_{\mathrm{m}}+\Sigma \Delta \mathrm{S}_{\mathrm{tr}}
$$

where the total entropy of melting is made up of a constant quantity and the contribution due to translational effects in the liquid phase. The translational contribution to the overall 
melting entropy can be further delineated into rotational entropy and conformational entropy. The conformational entropy is a measure of the flexibility of the molecule. The total entropy of melting equation can then be written as:

$$
\Delta \mathrm{S}_{\mathrm{m}}=\mathrm{C}-\mathrm{R} \ln \sigma+\mathrm{R} \ln \phi
$$

where $\mathrm{C}$ is a constant, $\sigma$ is molecular symmetry factor and $\phi$ is a molecular flexibility factor. Specific values were then developed for the molecular symmetry and flexibility factors. A least squares method was used to develop these values. The average of 245 values for which the symmetry and flexibility contributions were assumed to be 0 gave a value of $50 \mathrm{~J} / \mathrm{mole}^{\circ} \mathrm{K}$ for $\mathrm{C}$. Using this constant, symmetry and flexibility values were then developed for 930 compounds and 25 configurational parameters. The experimental data ranged from 9 to $588 \mathrm{~J} / \mathrm{mole}^{\circ} \mathrm{K}$, with the majority falling between 10 and $200 \mathrm{~J} / \mathrm{mole}^{\circ} \mathrm{K}$. The model produced estimates which have an average absolute error of $12.5 \mathrm{~J} / \mathrm{mole}^{\circ} \mathrm{K}$ for 1277 values for 934 compounds. This work included some variation in the data for approximately 300 compounds. As a result, multiple values for the entropy of melting for these compounds were used in the regression. The authors state that this value is "well within the experimental error that is normally associated with observed entropy of melting data".

The accuracy of the experimental data is a significant factor for any estimating technique. Many compounds have entropies of melting which are within a few percent of one another. However, a large number of compounds have reported values which vary widely. It is very difficult to attribute better or worse accuracy of measurement to various experimenters because of the large variability among many reference sources. As noted above, Dannenfelser made reference to either the difficulties in measuring entropy of melting data, or the gradation in quality of data in the literature. Several of the references 
from which experimental data was taken for this work also comment on the accuracy or grade the quality of experimental data. Lumsden (1966) included extensive comments on and comparisons of the experimental data used in his book. Where multiple values have been measured for specific thermodymanic properties, Lumsden discusses possible reasons for the discrepancies. Barin (1977) goes further and categorizes the accuracy of experimental data. The following grading scheme is used:
A: key values or equally well-established values;
B: "good values", no immediate need for redetermination
C: "moderately good values", redetermination desirable
D: "better than nothing".

This clearly points out the uncertainty associated with experimental values of thermochemical properties.

Examples of large differences in experimentally measured data are very common. Barin (1989) reports a value of $39.64 \mathrm{~J} / \mathrm{mole}^{\circ} \mathrm{K}$ for the entropy of melting of cadmium bromide. However, Knacke (1990) reports a value of $50.45 \mathrm{~J} / \mathrm{mole}^{\circ} \mathrm{K}$. This problem is further exacerbated by the value of $24.87 \mathrm{~J} / \mathrm{mole}^{\circ} \mathrm{K}$ in the CRC Handbook (1973-1974) because the Handbook is so widely used. Another case for which values differ significantly among experimental data is cadmium chloride. Respectively, Barin (1989), Knacke (1990), CRC (1973-1974) and Lange's Handbook (1979) report values of 37.81, 44.32, 26.368 and $35.82 \mathrm{~J} / \mathrm{mole}^{\circ} \mathrm{K}$. Since many practicing chemical engineers have ready access the $\mathrm{CRC}$ or Lange's Handbooks, it is clear that the variability in experimental data may have significant implications for equipment design.

One reason frequently cited for differences among various experimenters is the inclusion of solid phase tranistion data with the values reported for entropy of melting. Some experimenters feel that changes in the solid lattice are the beginning of the melting process 
because they represent increasing disorder. The logical conclusion of this disordering process is the complete loss of lattice integrity, i.e., the solid becomes a liquid. However, there are experimenters who have attempted to identify instances for which solid phase transitions may be appropriate for inclusion in entropy of melting results. Dworkin (1963) uses nomeclature which differentiates between high-temperature and low-temperature forms of crystalline structure. For example, barium chloride undergoes a solid phase transition at $1193 \mathrm{~K}$ and all crystalline structure is lost at $1235 \mathrm{~K}$. The entropy which includes the lower temperature transition has a value of $27.53 \mathrm{~J} / \mathrm{mole}^{\circ} \mathrm{K}$ while the higher "melting" entropy is $13.26 \mathrm{~J} / \mathrm{mole}^{\circ} \mathrm{K}$. Clearly the difference between these two values is significant. Another example, strontium chloride, illustrates this issue more clearly. Dworkin reports the entropy of melting at $1146 \mathrm{~K}$ to be $14.18 \mathrm{~J} / \mathrm{mole}^{\circ} \mathrm{K}$. A solid phase transition of $6.9 \mathrm{~J} / \mathrm{mole}^{\circ} \mathrm{K}$ is also reported at $1003 \mathrm{~K}$. However, Barin (1989) reports an entropy of melting of $14.14 \mathrm{~J} / \mathrm{mole}^{\circ} \mathrm{K}$ at $1147 \mathrm{~K}$, but no solid phase transition. Another example of melting data which is very difficult to measure is molybdenum sesquisulfide, $\mathrm{Mo}_{2} \mathrm{~S}_{3}$. This compound apparently undergoes numerous solid phase transitions prior to complete loss of crystalline structure. The reported value of the entropy of melting is a barely measurable $0.062 \mathrm{~J} / \mathrm{mole}^{\circ} \mathrm{K}$ at $2080 \mathrm{~K}$.

Most of the estimation techniques in the literature have been developed for organic materials. The first generalization, Walden's rule, which predicts the entropy of melting for organic compounds to be approximately $56.5 \mathrm{~J} / \mathrm{mole}^{\circ} \mathrm{K}$, was developed based on coal tar studies. However, there are some general "rules of thumb" for estimating thermochemical properties for inorganic compounds. Richard's rule predicts a constant value, $10.5 \mathrm{~J} / \mathrm{mole}^{\circ} \mathrm{K}$, for the entropy of melting of small, spherical compounds such as methane and neon. Other attempts to estimate the entropy of melting as hard sphere model compounds include Lennard-Jones (1939) whose work resulted in an estimate of 1.7R (14.134 J/mole $\left.{ }^{\circ} \mathrm{K}\right)$; the HSE model, as referenced by Bondi (1967) predicts a value 
of R (8.314 J/mole ${ }^{\circ} \mathrm{K}$ ); and Honguet-Higgins and Widom, as referenced by Bondi (1967), predicts a value of $1.64 \mathrm{R}\left(13.63 \mathrm{~J} / \mathrm{mole}^{\circ} \mathrm{K}\right)$. However, all of these models assume either no interaction, or minimal interaction, among molecules upon melting and no hinderance to free rotation in the liquid state. This model appears valid for molecules which can be characterized as small, hard spheres.

Felder and Rousseau (1986) presented an estimating technique which is applicable to a wide variety of compounds. Their formulas are:

$$
\begin{aligned}
& \approx 0.0092 \mathrm{Tm}(\mathrm{K}) \text { (Metallic compounds) } \\
\mathrm{Hm}(\mathrm{kJ} / \mathrm{mole}) & \approx 0.025 \mathrm{Tm}(\mathrm{K}) \text { (Inorganic compounds) } \\
& \approx 0.050 \mathrm{Tm}(\mathrm{K}) \text { (Organic compounds) }
\end{aligned}
$$

This implies that the entropies of melting are constants with the values of $9.2 \mathrm{~J} / \mathrm{mole}^{\circ} \mathrm{K}, 25$ $\mathrm{J} / \mathrm{mole}^{\circ} \mathrm{K}$ and $50 \mathrm{~J} / \mathrm{mole}^{\circ} \mathrm{K}$ for metallic, inorganic and organic compounds, respectively. The value of $50 \mathrm{~J} / \mathrm{mole}^{\circ} \mathrm{K}$ approximates Walden's rule which appears to be somewhat high compared to many experimental values. However, when more complicated polymers and other complex organic compounds are considered, this value is not bad as an average estimate. This formula also allows differences in melting temperatures to contribute to the overall heat of melting. Moreover, this is the only method which has been presented for estimating the heat of melting for inorganic materials which has been widely disseminated.

\section{Development of the Group Contribution Method}

The approach developed in the present work is the use of multiple regression analysis to give a "best" fit for the entropy of melting, $\Delta \mathrm{S}_{\text {melting. This approach requires that the }}$ melting temperature of the compound to be estimated is known. Fortunately, this is one of the least difficult measurements to make for chemical compounds. This approach also concentrates on the group contributions to the symmetry of the molecule rather than 
attempting to correlate intermolecular forces. Since the negativity of various anions must be compensated by the manner in which they are distributed within the molecule, the determination of group contributions to the entropy of melting should be consistent for the same cation/anion charge distributions. The form of the equation is:

$$
\mathrm{Sm}=\mathrm{a}_{0}+\sum \mathrm{n}_{\mathrm{j}} \Delta_{\mathrm{ij}}
$$

The parameters, $\Delta_{\mathrm{ij}}$ denoted here by $\mathrm{b}$, will be estimated using the standard least squares approach

$$
\mathbf{b}=\left(\mathbf{X}^{\mathrm{T}} \mathbf{X}\right)^{-1} \mathbf{X}^{\mathrm{T}} \mathbf{Y}
$$

where $\mathbf{X}$ is a matrix in which the $i^{\text {th }}$ row and $j^{\text {th }}$ column contains $n_{i, j}$, the number of occurrences of the $j^{\text {th }}$ group in compound $i$, and $y$ is the vector in which the $i^{\text {th }}$ element contains the empirical value for the entropy of fusion for compound $i$.

The error vector $\mathbf{e}$ is defined as

$$
\mathbf{e}=\mathbf{y}-\mathbf{X b}
$$

that is to say, the calculated value subtracted from the experimental value for the heat capacity. The error vector will then be used to calculate the standard deviations of each group as determined by the variance-covariance matrix

$$
\mathbf{S}=\left[\mathbf{e}^{\mathrm{T}} \mathbf{e} / \mathrm{n}-\mathrm{p}-1\right]\left[\mathbf{X}^{\mathrm{T}} \mathbf{X}\right]^{-1}
$$

where $\mathrm{n}$ is the number of salts in the regression and $\mathrm{p}$ is the number of group contribution parameters being estimated.

\section{Procedure for Estimation Using the Proposed Method}


The proposed method for estimating the entropy of fusion is applicable to inorganic compounds and is used by performing a stepwise application of the group contributions based on the chemical composition of the compound for which the estimate is being made. A total of 557 compounds were used in the linear regression for determining the values of the group contributions to the entropy of melting. Their structures were broken down into 114 cationic single element groups, 1 cationic functional group, 16 anionic single element groups, 23 anionic functional groups, 5 anionic inorganic polymer groups and 1 ligand group. The anionic polymer groups include 4 sulfur polymers and one silicon polymeric group. The polymeric constituents display behavior which is analagous to more conventional carbon polymers. Hunter (1963) states that a number of inorganic materials will form polymers. Examples include compounds such as $\mathrm{H}_{2} \mathrm{~S}_{2}$, in which the sulfur dimer behaves the same as a single sulfur atom. Phosphorus also displays polymeric characteristics, especially when combined with sulfur. In addition, many of these compounds form rings and double bonds which are also usually considered to be polymeric behaviour. Sulfur, whose polymeric characteristics are well known, represents the majority of the inorganic polymers in this work. However, other combinations which may display polymeric behavior include boron or phosphorus and oxygen.

The following illustrates the procedure for using this technique.

Step 1: Write the molecular formula for the inorganic liquid compound.

Step 2: Based on the molecular formula, break the compound into appropriate cationic, anionic or ligand functional groups as given in Table 1 (due to length, Table 1 is included at the end of this paper). Values for the contributions to the entropy of melting, $\Delta_{\mathrm{ij}}$, are 
given for a variety of models which will be discussed later in this section. Using the numerical value listed for each constituent, multiply by the number of times the constituent appears in the molecular formula.

Step 3: Sum the numerical values from step 2 and add the value of $a_{0}$, the constant. Step 4: Calculate $S_{m}$ for any absolute temperature at the melting temperature for the compound using equation 11 .

Due to the difficulties associated with estimating entropies of melting, and the uncertainty inherent in the experimental data, a variety of models were examined in this work. These include:

$$
\begin{aligned}
& \text { Model 1: } \mathrm{S}_{\text {mest }}=\sum \mathrm{n}_{\mathrm{j}} \Delta_{\text {Smij }} \\
& \text { Model 2: } \mathrm{S}_{\text {mest }}=\mathrm{a}_{0}+\sum \mathrm{n}_{\mathrm{j}} \Delta_{\text {Smij }} \\
& \text { Model 3: } \mathrm{S}_{\text {mest }}=\operatorname{Re}^{\left(\mathrm{a}_{0}+\sum \mathrm{n}_{\mathrm{j}} \mathrm{s}_{\text {mij }}\right)} \\
& \text { Model 4: } \mathrm{S}_{\text {mest }}=\left(\mathrm{a}_{0}+\sum \mathrm{n}_{\mathrm{j}} \Delta_{\text {Smij }}\right)+1-\operatorname{Rin} \varphi
\end{aligned}
$$

Where $a_{0}$ is a constant derived from the least squares regression, $n_{j}$ is the number of times group $\mathrm{j}$ appears in compound $\mathrm{i}$ and $\Delta_{\mathrm{Smij}}$ is the contribution attributable to group $\mathrm{j}$ in compound $\mathrm{i} ; \mathrm{R}$ is the gas constant, $8.314 \mathrm{~J} / \mathrm{mole}^{\circ} \mathrm{K}$, and $\varphi$ is the ratio of the product of the anionic electronegativity and size to the product of the cationic electronegativity and size.

There is an interesting implication when considering Models 1 and 2. Model 2 implies that there is some constant, $a_{0}$, which is associated with the melting of a substance and is 
totally independent of the chemical constituents of, and molecular interactions within the substance. The most fundamental definition of entropy is that developed by Boltzman:

$$
\mathrm{S}=\mathrm{k} \ln \mathrm{W}
$$

where $\mathrm{S}$ is the entropy, $\mathrm{k}$ is Boltzman's constant and $\mathrm{W}$ is the multiplicity, or number of quantum states, of the system. W may be better explained as the representation of the distribution of energy states within the system under consideration.

We can use statistical thermodynamics of gases to further explain the relationship of various properties which make up the quantum states of a system. Using the quantity $Q$, which represents the molecular partition function, we can rewrite equation 19 as:

$$
\mathrm{S}=\mathrm{k} \ln \mathrm{Q}
$$

We can further delineate the contributors to the quantity $Q$ by defining the following quantities:

$$
\mathrm{Q}=\mathrm{Q}_{\mathrm{tran}} \cdot \mathrm{Q}_{\mathrm{rot}} \cdot \mathrm{Q}_{\mathrm{vib}} \cdot \mathrm{Q}_{\mathrm{el}} \cdot \mathrm{Q}_{\mathrm{nuc}}
$$

where $\mathrm{Q}_{\mathrm{tran}}$ is the translational contribution, $\mathrm{Q}_{\mathrm{rot}}$ is the rotational contribution, $\mathrm{Q}_{\mathrm{vib}}$ is the vibrational contribution, $\mathrm{Q}_{\mathrm{el}}$ is the contribution due to the electronic states and $\mathrm{Q}_{\mathrm{nuc}}$ is the contribution due to nuclear states. This form of the equation indicates that the partition function has a product structure. Because we are taking the log of the overall partition function in equation 20 , these quantities become additive as logarithmic quantities. Substituting the quantities in equation 21 , we may rewrite equation 20 as:

$$
\mathrm{S}=\mathrm{k}\left(\ln \mathrm{Q}_{\mathrm{trans}}+\ln \mathrm{Q}_{\mathrm{rot}}+\ln \mathrm{Q}_{\mathrm{vib}}+\ln \mathrm{Q}_{\mathrm{el}}+\ln \mathrm{Q}_{\mathrm{nuc}}\right)
$$

Model 2, which has a constant, implies that one or more of the quantities in equation 22 are independent of the constituents of compounds and are only an artifact of the phase 
change from solid to liquid. Since equation 22 has been developed for an ideal gas, there may also be an additional term, or terms, which represent a fundamental change for all materials when the solid to liquid phase change occurs and as such may be represented as a constant to which additional contributions based on the chemical makeup of the material are added.

Model 1, equation 16 , is a least squares regression on the experimental data without a constant. This model is made up of only the summation of the group contributions for each compound being estimated. This approach assumes that the entropy of melting is entirely dependent on the constituents of the compound. Further, it assumes that there is no common, or intrinsic entropy associated with the solid to liquid phase change regardless of the compound's constituent elements or groups. The y vector is made up of the experimental values, or in the case of significant variations in the reported entropies for the same compound, an average entropy of melting. The regression method is then used to determine the group contribution estimating factors. The results of this model are a standard deviation of $12.01 \mathrm{~J} /$ mole $^{\circ} \mathrm{K}$ and an average absolute difference between the calculated and experimental entropies of melting of $7.05 \mathrm{~J} / \mathrm{mole}^{\circ} \mathrm{K}$. The advantages of this method are that it is very easy to apply, using only the group contribution values listed in Table 1, and the many constituent elements or groups into which complex compounds may be broken.

Model 2, equation 16, a straightforward least squares regression on the experimental data with a constant, resulted in a standard deviation of $11.42 \mathrm{~J} / \mathrm{mole}^{\circ} \mathrm{K}$ and an average 
absolute difference of $6.66 \mathrm{~J} / \mathrm{mole}^{\circ} \mathrm{K}$. This technique uses the experimental data as the $\mathrm{y}$ vector and the regression method is then applied. For compounds with multiple, or widely varying values reported in the literature an average value has been used. While this may not result in a value which is close to any of the reported data, it does provide a value for the regression which is bracketed by the reported data. This approach has been taken for all of the models which have been evaluated. The advantages of Model 2 are the ease of use and the uncomplicated information it provides. The compounds are broken into the functional elements or groups, the appropriate group contributions values multiplied by the number of occurences and the individual resulting values summed. Unfortunately, this model does not take any shape, charge or intermolecular forces explicitly into account. However, since melting entropy is not a strong function of temperature and all data is assumed to be at standard pressure, this may not be a significant shortcoming.

The improvement of the estimated values as a result of including the constant would appear to indicate that there is some entropy which is associated with the phase change from a solid to a liquid which is independent of the material undergoing this change. In order to determine if the $\mathrm{a}_{0}$ value is in fact non-zero, a test for statistical significance was done. We can perform an $\mathrm{F}$ test to statistically compare Models 1 and 2 . Using the sum of squares and the mean square values for both models, we can pose the null hypothesis that Model 1 describes the data better than Model 2. The calculated $F$ value is 42.56 which is much larger than the $\mathrm{F}$ value of 6.63 at the $1 \%$ confidence level. From this we cannot deduce that Model 2 is the correct model, but we can say with $99 \%$ confidence that Model 2, which includes a constant, is a better description of the data than Model 1, 
which does not include a constant. Hirschfelder (1937) contents that there is a constant associated with melting which he termed to be "communal entropy". Experimental values cited by Hirschfelder indicate that this should be true, and that the value of this constant should be $\mathrm{R}$, the gas constant. The present work, based on the experimental data used, gives a value of $2.5187 \mathrm{~J} / \mathrm{mole}^{\circ} \mathrm{K}$, or $0.303 \mathrm{R}$.

Models 3 and 4 (equations 17 and 18, respectively) both introduce logrithmic or exponential terms into the estimate and both use $\mathrm{R}$, the gas constant as a "correction" factor. Model 3 produced estimates with a standard deviation of $13.55 \mathrm{~J} / \mathrm{mole}{ }^{\circ} \mathrm{K}$ and an absolute average difference of $7.39 \mathrm{~J} / \mathrm{mole}^{\circ} \mathrm{K}$. Model 4 produced estimates with a standard deviation of $11.55 \mathrm{~J} / \mathrm{mole}^{\circ} \mathrm{K}$ and an absolute average difference of 6.72 $\mathrm{J} /$ mole $^{\circ} \mathrm{K}$.

Comparing these forms, the best fit of the experimental data was provided by Model 2 . The average absolute difference between the estimated and experimental entropy of melting for the 557 compounds evaluated is $6.66 \mathrm{~J} /$ mole $^{\circ} \mathrm{K}$. In addition, this is the easiest and most straightforward method to use. The constant and values for the group contributions are given in Table 1. Also included in this table are the standard deviations for each of the contribution quantities. Since virtually no improvement was found for any of the more complex forms, it appears that no additional information can be extracted from this set of data as it appears in the literature. For Model 2, the value of the statistical quantity $r^{2}$, or the multiple correlation coefficient, is 0.825 . If the predicted values from the model exactly matched the experimental values then the value of $r^{2}$ would be 1 . 
Therefore, the value of 0.825 indicates that the values determined by use of the model agree well with those observed experimentally. A total of 8 compounds have estimated values which exceed three standard deviations difference when compared to experimental values. These compounds include $\mathrm{Al}_{2} \mathrm{Te}_{3}, \mathrm{Bi}_{2} \mathrm{O}_{3}, \mathrm{Bi}_{2} \mathrm{Te}_{3}, \mathrm{Na}_{5} \mathrm{Al}_{3} \mathrm{~F}_{14}, \mathrm{ReOF}_{5}, \mathrm{SO}_{2}, \mathrm{WOCl}_{4}$ and $\mathrm{WOF}_{4}$. When these values are removed from the comparison, the average absolute difference between the experimental and calculated values is $6.02 \mathrm{~J} / \mathrm{mole}^{\circ} \mathrm{K}$.

These values are significant improvements to the existing estimating methods in the literature. Chickos (1990, 1991 and 1995) reported average absolute differences of 7.74 $\mathrm{J} /$ mole $^{\circ} \mathrm{K}$ for 191 hydrocarbons; $8.4 \mathrm{~J} / \mathrm{mole}^{\circ} \mathrm{K}$ for the previous 191 compounds and an additional 225 monosubstititued and 233 multisubstitutued hydrocarbons; and $\mathrm{J} / \mathrm{mole}^{\circ} \mathrm{K}$ for 63 polymers, respectively. Dannenfelser (1996) reported an absolute average difference of $12.5 \mathrm{~J} /$ mole $^{\circ} \mathrm{K}$ for 930 organic compounds. Chickos and Dannenfelser used only organic or substituted organic compounds for their work. The present work also covers a much wider range of elements and functional groups, including inorganic polymers, than any previously reported work. The average absolute error for the estimated values is significantly smaller than those reported for organic compounds. This coupled with the extremely wide range of compounds and extremes in melting points greatly extends the estimation capability for entropy of melting.

Finally, the predictive value of the model and the group contibution constants has been evaluated by estimating the values of several compounds not included in the regression analysis. Table 2 gives the experimental and calculated values for 6 compounds not used 
as part of the regression. The average absolute error is $3.717 \mathrm{~J} / \mathrm{mole}^{\circ} \mathrm{K}$ and the average absolute percent error is $15.16 \%$ for these compounds. The largest difference between an observed and calculated value is for cuprous cyanide, which has a difference of 7.932 $\mathrm{J} / \mathrm{mole}^{\circ} \mathrm{K}$. One note of interest, the value for water, $\mathrm{H}_{2} \mathrm{O}$, is determined by using value of the $\mathrm{H}^{+}$ion taken twice rather than a single $\mathrm{H}^{+}$ion and an $\mathrm{OH}^{-}$ion. One of the reasons for this is that, in the solid, the hydrogen and oxygen behave as individual contributors and not as a hydroxyl group and an individual proton. The accuracy of the estimated values to the experimentally observed values indicate that the model and the constants represent a useful method of estimating entropies of melting for inorganic compounds. However, care must be used in determining the functional elements or groups.

Table 2

\begin{tabular}{|l|r|r|r|r|r|r|r|}
\hline \multicolumn{6}{|c|}{ Table 2 Comparison of Calculated and Experimental Values of Entropy of Melting } \\
\hline & & & & & & & \\
\hline Cmpd & & $\begin{array}{l}\text { Exp. } \\
\text { Data }\end{array}$ & & $\begin{array}{l}\text { Calc } \\
\text { Value }\end{array}$ & & $\%$ Diff & \\
\hline & & $\mathrm{J} /$ mole $^{\circ} \mathrm{K}$ & & $\mathrm{J} /$ mole $^{\circ} \mathrm{K}$ & & & \\
\hline $\mathrm{HI}$ & & 12.929 & & 17.3814 & & 33.81 & \\
\hline $\mathrm{P} 2 \mathrm{O} 3$ & & 23.691 & & 24.057 & & 1.55 & \\
\hline $\mathrm{MoCl} 5$ & & 40.32 & & 34.214 & & -15.14 & \\
\hline $\mathrm{Cu2}(\mathrm{CN}) 2$ & & 30.286 & & 38.2181 & & 26.19 & \\
\hline $\mathrm{NH} 4 \mathrm{I}$ & & 25.388 & & 23.1099 & & -8.97 & \\
\hline $\mathrm{H} 2 \mathrm{O}$ & & 22.01 & & 20.843 & & -5.3 & \\
\hline
\end{tabular}


Group contribution techniques have been extensively studied for estimating heat capacities. According to Reid (1987), estimation methods applicable to liquids fall into four general categories; theoretical, group contribution, corresponding states and Watson's thermodynamic cycle.

As noted by Mostafa (1995), a number of authors have developed estimation techniques for ideal gases that give reasonably good agreement with experimental data. There are several fundamental assumptions which are valid for organic ideal gases which contribute to this agreement. The absence of molecular interaction is one such assumption. Joback (1984), Yoneda (1979) and Thinh (1976) all developed group contribution techniques for estimating the heat capacity of hydrocarbons in the ideal gas state. Because of the lack of direct applicability of the ideal gas heat capacity to that of liquids, these methods will not be discussed in detail. However, because these methods have been shown to be accurate over a wide temperature range, we will examine the functional form of the heat capacity equation recommended in each method.

Joback (1984) suggested the use of constants as the correction factors for each of the specific contributions. This equation for $\mathrm{C}_{\mathrm{p}}$ in $\mathrm{J} / \mathrm{mole}{ }^{\circ} \mathrm{K}$ is of the form

$$
\begin{gathered}
C_{p}=\left(\sum n_{j} \Delta_{a}-37.93\right)+\left(\sum n_{j} \Delta_{b}+0.21\right) T \\
+\left(\sum n_{j} \Delta_{c}-3.91 \times 10^{-4}\right) T^{2}+\left(\sum n_{j} \Delta_{d}+2.06 \times 10^{-7}\right) T^{3}
\end{gathered}
$$

Joback then developed a set of constants, $\Delta$, which represented the contribution of specific groups to this equation. Yoneda (1979) uses a simpler form of the heat capacity equation 
in $\mathrm{J} / \mathrm{mole}^{\circ} \mathrm{K}$. The following is the form suggested by Yoneda

$$
\mathrm{C}_{\mathrm{p}}=\sum \mathrm{n}_{\mathrm{j}} \Delta_{\mathrm{a}}+\left(\sum \mathrm{n}_{\mathrm{j}} \Delta_{\mathrm{b}}\right)(\mathrm{T} / 1000)+\left(\sum \mathrm{n}_{\mathrm{j}} \Delta_{\mathrm{c}}\right)(\mathrm{T} / 1000)^{2}
$$

As with Joback, Yoneda then developed a set of constants which could be plugged into equation 24 to estimate the heat capacity of specific compounds. Thinh (1976) suggests a more complicated form of the heat capacity equation

$$
C_{p}=\sum n_{j}\left[A+B_{1} \exp \left(-C_{1} / T^{n l}\right)-B_{2} \exp \left(-C_{2} / T^{n 2}\right)\right]
$$

The forms of all of these equations allow for the estimation of heat capacity over some temperature range. All of these methods predict ideal gas heat capacities of organic compounds within $5 \%$ of the experimental values at several temperatures. However, there are some specific compounds such as dimethylbutene, methyl ethyl ketone and octofluorocyclobutane, which show relatively large anomalies at all temperatures for one or all of these estimation methods.

Mostafa (1996) used a similar form of the heat capacity equation in $\mathrm{J} / \mathrm{mole}{ }^{\circ} \mathrm{K}$ for estimating the heat capacity of a large number of inorganic solids. The general form suggested by Mostafa is

$$
C_{p}=a+b T+c / T^{2}+d T^{2}
$$

where the coefficients $a, b, c$ and $d$ were determined using a least squares regression and experimental data at several temperatures. This method gives very good agreement with experimental data (mean error $3.18 \%$ at $298^{\circ} \mathrm{K}$ ) over a fairly wide range of temperatures, $298-600 \mathrm{~K}$, but may begin to diverge significantly for many compounds beyond this range (mean error $8.17 \%$ at upper temperature). The literature indicates that for many gases and 
solids, sufficient empirical data exists to fit heat capacity data to a polymonial such as equation 26 in which heat capacity changes as a function of temperature.

One of the earliest techniques for estimating heat capacities for liquids is Kopp's rule.

Developed in 1864 , this method uses the following values to estimate heat capacities for both solids and liquids in units of $\mathrm{J} / \mathrm{mole}^{\circ} \mathrm{K}$ : 


$\begin{array}{ccr}\text { Elements } & \text { Solids } & \text { Liquids } \\ \text { C } & 7.53 & 11.72 \\ \text { H } & 9.62 & 17.99 \\ \text { B } & 11.30 & 19.66 \\ \text { Si } & 15.90 & 24.27 \\ \text { O } & 16.74 & 25.10 \\ \text { F } & 20.92 & 29.29 \\ \text { P or S } & 22.59 & 30.96 \\ \text { All others } & 25.94 & 33.74\end{array}$

Although this technique is only valid around room temperature $\left(20^{\circ} \mathrm{C}\right)$, it is one of the first attempts to attribute thermodynamic properties to a compound based on a summation of the contributions of it's constituents.

Johnson and Huang (1955) suggested that the Hougen and Watson modification of Kopp's rule could be extended through the homologous series hydrocarbons such as alcohols, acids and esters, to determine molar heat capacities at $20^{\circ} \mathrm{C}$. Johnson used data summarized by Chow and Bright (1953). The form of equation suggested by Johnson may be expressed as:

$$
C_{p}=\sum n_{i j} \Delta_{c p i j}
$$

where $n_{\mathrm{ij}}$ is the number of times functional group $\mathrm{j}$ occurs in compound $\mathrm{i}$ and $\Delta_{\mathrm{Cpij}}$ is the value of the specific functional group $\mathrm{j}$ in compound $\mathrm{i}$ and units for $\mathrm{Cp}$ are $\mathrm{J} / \mathrm{mole}^{\circ} \mathrm{K}$. The method then takes the constituent parts of the compound to be estimated and assigns the 
appropriate values for the constituent parts, sums the parts and provides an estimate of the heat capacity of that organic liquid. This technique gives an average deviation of $5 \%$ for 84 liquid organic compounds. However, it should be noted that 13 of the 84 values, primarily benzene derivatives and esters of chloroacetic acid, showed deviations of greater than $10 \%$.

Bondi (1966) estimated the constant volume heat capacity of various organic liquids using the "lattice" heat capacity of the liquid. The method involves the estimation of various rotational and translational components of small molecules and short-chain polymers. The general equation may be expressed as:

$$
\mathrm{C}_{\mathrm{vi}}(\mathrm{T})=\mathrm{C}_{\mathrm{tr} \lambda}(\mathrm{T})+\mathrm{C}_{h r}(\mathrm{~T})+\mathrm{C}_{b}(\mathrm{~T})
$$

where $\mathrm{C}_{\mathrm{v} \lambda}$ is the liquid state contribution to overall constant volume heat capacity, $\mathrm{C}_{\mathrm{tr} \lambda}$ is the contribution due to translational oscillations, $\mathrm{C}_{\mathrm{hr}}$ is the contribution due to hindered external rotation and $C_{b}$ is that due to work expended in cooperative motions of many molecules at high packing densities. These parts may then be used to estimate the heat capacity in $\mathrm{J} / \mathrm{mole}^{\circ} \mathrm{K}$ of more complex molecules. The basic technique involves the use of rotational and translational contributions to heat capacity which can be based on several criteria including molecular polarity, rigidity and internal rotation. Unfortunately, a significant amount of molecular information, such as ideal heat capacity, principle moments of inertia, accentricity factors and energy of vaporization must be known before this method can be employed. While this method does not directly take the constituents of the molecules into account, it does recognize that the constituents contribute to the 
various modes of rotation and translation. Agreement between calculated and experimental heat capacities appear to be within approximately $6-10 \%$ for this method.

Shaw (1969) used a least squares regression technique to correlate empirical heat capacity information for 63 "groups" of organic, organic-halide, organo-amine and thio-organic combinations. Equation 27 represents the general form of the heat capacity equation used. Using these group factors, the heat capacity of approximately 120 organic compounds were estimated. Shaw pointed out that the success of additivity methods depend on the quality and extent of the measured data and that there are significant gaps in the experimental data. He cited several examples such as quinoline, tetrahydropyrole and furan for which estimates could not be made because of insufficient experimental information. This technique, while limited to organics, gives excellent estimates at $25^{\circ} \mathrm{C}$, typically $\pm 1.0 \mathrm{cal} / \mathrm{mole}^{\circ} \mathrm{K}\left(4.2 \mathrm{~J} / \mathrm{mole}^{\circ} \mathrm{K}\right)$ and in all cases for the data reported within \pm $1.5 \mathrm{cal} / \mathrm{mole}^{\circ} \mathrm{K}\left(6.3 \mathrm{~J} / \mathrm{mole}^{\circ} \mathrm{K}\right)$

Chueh and Swanson (1973) extended the work of Johnson and Huang and Shaw to temperatures other than standard conditions. Their method estimates the heat capacity of the liquid at a reference state, typically $298^{\circ} \mathrm{K}$. Their equation is a thermodynamic relationship which has the following form:

$$
\mathrm{C}_{\mathrm{pl}}=\mathrm{dH}_{\mathrm{s}} / \mathrm{dT}=\mathrm{C}_{\mathrm{pg}}{ }^{*}-\mathrm{d} \lambda / \mathrm{Dt}-\mathrm{d}\left(\mathrm{H}^{*}-\mathrm{H}_{\mathrm{sg}}\right) / \mathrm{dT}
$$

where $\mathrm{C}_{\mathrm{pl}}$ is either the saturated liquid heat capacity, or the constant pressure liquid heat capacity since these are in very good agreement except near the critical temperature, $\mathrm{C}_{\mathrm{pg}}{ }^{*}$ is the ideal vapor heat capacity, $\lambda$ is the heat of vaporization and the remaining term can 
be estimated using the critical compressibility of the compound in question. The organic molecule is then broken into its constituent parts in accordance with a set of 36 specific groups. By adding the contribution for each group, a heat capacity at the desired temperature can be estimated. Based on the evaluation of approximately 150 organic compounds, this value is typically within $2-3 \%$ of the observed value. However, in order to estimate the heat capacity at some temperature other than the reference, the saturated liquid heat capacity, the heat of vaporization at the reference temperature and the critical temperature for the compound must be known.

With the exception of Chueh and Swanson, all of the methods discussed above are limited to specific temperatures, or at best, a very narrow range of temperatures. Even more limiting is the fact that all of these estimating techniques are applicable only to organic liquids.

\section{Development of Method}

For the present work, the functional form of the heat capacity equation

$$
C_{p}=a_{0}+\sum n_{j} \Delta_{c i j}
$$

for which $a_{0}$ is a constant, $n_{j}$ is the number of occurences of group $j$ in compound $i$ and $\Delta_{\text {Cpij }}$ is the contribution of group $j$ in compound $i$. The constant $a_{0}$ and each group contribution $\Delta_{\mathrm{Cpij}}$ which will be determined by a multiple linear regression technique. This form has been chosen because the vast majority of the experimental data for inorganic liquids are reported as a constant from the melting point through the entire range of 
measurement rather than as a fuction of temperature. The least squares method which will be used can be expressed in matrix form as

$$
\mathbf{b}=\left[\mathbf{X}^{\mathrm{T}} \mathbf{X}\right]^{-1} \mathbf{X}^{\mathrm{T}} \mathbf{y}
$$

where $\mathbf{b}$ is the vector of calculated predictions of $\Delta_{\mathrm{j}}$, respectively, $\mathbf{X}$ is a matrix in which the element in the $i^{\text {th }}$ row and $j^{\text {th }}$ column contains $n_{j}$, where $n_{j}$ denotes the number of ocurrences of group $\mathrm{j}$ in compound $\mathrm{i}$, and $\mathbf{y}$ is the vector which contains the experimental values of $C_{p}$, the heat capacity of compound $i$. The error vector $\mathbf{e}$ is defined as

$$
\mathbf{e}=\mathbf{y}-\mathbf{X b}
$$

that is to say, the calculated value subtracted from the experimental value for the heat capacity. The error vector will then be used to calculate the standard deviations of each group as determined by the variance-covariance matrix

$$
\mathbf{S}=\left[\mathbf{e}^{\mathrm{T}} \mathbf{e} / \mathrm{n}-\mathrm{p}-1\right]\left[\mathbf{X}^{\mathrm{T}} \mathbf{X}\right]^{-1}
$$

where $\mathrm{n}$ is the number of salts in the regression and $\mathrm{p}$ is the number of group contribution parameters being estimated. The standard deviation for each group contribution is determined by taking the square root of each value of the diagonal in the $\mathrm{S}$ matrix.

\section{Procedure for Estimation Using the Proposed Method}

The proposed technique for estimating $C_{p}$ for an inorganic compound at its melting point is used by performing a stepwise application of the group contributions based on the chemical composition of the compound for which the estimate is being made. Using equation 30 ,

$$
C_{p}=a_{0}+\sum n_{j} \Delta_{C p i j}
$$


where the least squares method gives a value of -15.0497 for $\mathrm{a}_{0}$ and Table 1 gives the values for the cationic and anionic elements and functional groups.

A total of 481 compounds which were broken down into 104 cationic elements, one cationic functional group, 16 anionic elements, 24 anionic functional groups and one ligand group. Included among the anionic functional groups are several inorganic polymers including 4 sulfur polymers and one silicon polymer which exhibit anionic chemical behavior. Hunter (1963) provides additional information concerning inorganic polymers. The most prevalent appear to be sulfur, although combinations of elements such as boron or phosphorus and oxygen may also form polymers which also exhibit anionic behavior.

The following illustrates the procedure for using this technique.

Step 1: Write the molecular formula for the inorganic liquid compound.

Step 2: Based on the molecular formula, break the compound into appropriate cationic, anionic or ligand functional groups as given in Table 1. Using the numerical value listed for each constituent, multiply by the number of times the constituent appears in the molecular formula.

Step 3: Sum the numerical values from step 2 and add the value of $a_{0},-15.0497$.

Step 4: Calculate $C_{p}$ for any absolute temperature between the melting and boiling points for the compound using equation 30 
The value of $\mathrm{r}^{2}$, the multiple correlation coefficient, is 0.982 . If the predicted values were all identical to the observed values, the value of $r^{2}$ would be 1 . The value of 0.982 indicates that the calculated values are, overall, very close to the observed values for the set of data used in this regression. Figure 3.3 shows the distribution of the standard deviation of the estimated values. A total of six estimated values have differences of greater than 3 standard deviations $(3 \sigma)$ when compared to the experimental data.

Because greater than $90 \%$ of the experimental data in the literature is given as a constant which is then multiplied by the desired temperature change to determine heat or enthalpy change, no dependency of $C_{p}$ on $T$ has been developed. As Reid(1987) points out, liquid heat capacities are not strong functions of temperatures except above reduced temperatures, $T_{r}$ or the ratio of the desired temperature and the critical temperature, of approximately 0.8 . For many inorganic liquids, critical temperatures have not been experimentally determined and there appear to be few, if any, estimating techniques in the literature. With these limitations in mind, the use of "constant" heat capacities for the entire liquid range of inorganic compounds had been used as the basis for the proposed estimating technique.

Kopp's rule gives reasonably good estimates for many inorganic liquids. However, for most compounds, including complex oxides and halides, the proposed method gives better estimates. Overall, Kopp's rule has a mean absolute difference of $10.15 \%$ for the 481 compounds evaluated with 56 compounds having absolute differences of $20 \%$ or greater 
when compared to the experimental values. The proposed method has a mean absolute difference of $6.03 \%$, or $7.98 \mathrm{~J} / \mathrm{mole}^{\circ} \mathrm{K}\left(1.91 \mathrm{cal} / \mathrm{mole}^{\circ} \mathrm{K}\right)$, with 18 compounds having absolute differences of $20 \%$ or greater when compared to the experimental values. A more detailed analysis of the results indicates a standard deviation $(\sigma)$ of $14.68 \mathrm{~J} / \mathrm{mole}^{\circ} \mathrm{K}$. Six compounds exhibit deviations which are $3 \sigma$ or more from the experimental values. The include $\mathrm{ScF}_{3}, \mathrm{NbF}_{5}, \mathrm{UO}_{2}, \mathrm{CaB}_{2} \mathrm{O}_{4}, \mathrm{Na}_{5} \mathrm{Al}_{3} \mathrm{~F}_{14}$ and $\mathrm{Na}_{4} \mathrm{SiO}_{4}$. With these 6 compounds removed from the analysis, the remaining 475 compounds have an average absolute error of $5.77 \%$ or $7.4 \mathrm{~J} / \mathrm{mole}^{\circ} \mathrm{K}\left(1.77 \mathrm{cal} /\right.$ mole $\left.^{\circ} \mathrm{K}\right)$. These results are consistent with other estimating techniques which have been developed for organic liquids. Further, this method requires only that the melting temperature of the compound be known or measured to assure that the temperature at which an evaluation will be made is within the liquid range for the compound and that the compound be simplified to subunits which are listed in Appendix Table A-5.

Table 3 is a comparison of 10 compounds which were not used in the development of the group contribution constants. Overall, agreement is good between the experimental values and the estimates using the proposed method. The compounds for which the model estimates deviate most from the experimental values are $\mathrm{NH}_{5} \mathrm{~F}_{2}$ and $\mathrm{VCl}_{4}$ which have absolute differences of $12.689 \mathrm{~J} / \mathrm{mole}^{\circ} \mathrm{K}$ and $15.135 \mathrm{~J} / \mathrm{mole}^{\circ} \mathrm{K}$ and absolute percent differences of $8.91 \%$ and $9.36 \%$, respectively. The average absolute difference between the experimental and estimated values for liquid heat capacities is $5.47 \mathrm{~J} / \mathrm{mole}^{\circ} \mathrm{K}$ and the average absolute percent difference is $4.29 \%$.

Table 3 


\begin{tabular}{|c|c|c|c|}
\hline Table 3 & Evaluation of Compo & Used In $\operatorname{Re}$ & \\
\hline & & & \\
\hline Cmpd & $\begin{array}{l}\text { Exp. } \\
\text { Data }\end{array}$ & Calc. Val. & $\%$ Diff. \\
\hline & $\mathrm{J} / \mathrm{mole}^{\circ} \mathrm{K}$ & $\mathrm{J} /$ mole $^{\circ} \mathrm{K}$ & \\
\hline $\mathrm{SiHCl} 3$ & 130.34 & 128.101 & -1.72 \\
\hline $\mathrm{NH} 4 \mathrm{OH}$ & 119.7 & 115.274 & -3.7 \\
\hline NH5F2 & 142.4 & 155.089 & 8.91 \\
\hline $\mathrm{RbHF} 2$ & 117.9 & 119.425 & 1.29 \\
\hline $\mathrm{H} 2 \mathrm{CS} 3$ & 148.53 & 153.93 & 3.46 \\
\hline $\mathrm{CdSb}$ & 59.83 & 63.5268 & 6.18 \\
\hline $\mathrm{VCl} 4$ & 161.712 & 176.847 & $\overline{9.36}$ \\
\hline $\mathrm{VOCl} 3$ & 150.624 & 146.13 & -2.98 \\
\hline $\mathrm{HF}$ & 43.1 & 42.62 & -1.11 \\
\hline HNO3 & 111.7 & 107.06 & -4.16 \\
\hline
\end{tabular}

Some care must be used when applying the method to compounds which have grouping of elements which behave as functional groups. Examples are groups such as thionyl and carbonyl groups. While the summing of the individual elements will give a reasonable value, groups such as these may exhibit behavior which is significantly different than this estimate.

The proposed method of using group contributions provides estimates of heat capacities for inorganic liquids which have an absolute error of $6.59 \%$ when compared to experimental values for 481 compounds. The exclusion of statistical outliers $(>3 \sigma)$ improves the absolute average difference to $7.4 \mathrm{~J} / \mathrm{mole}^{\circ} \mathrm{K}$ or $5.77 \%$ for 476 inorganic liquids. The method provides group contribution estimates for 104 cationic elements, 1 cationic functional group, 16 anionic elements, 24 anionic functional groups and one ligand group. Included in the anionic functional groups are 5 inorganic polymers which 
exhibit anionic chemical behavior. By comparison, use of Kopp's rule generates estimates which have an absolute error of $13.43 \mathrm{~J} / \mathrm{mole}^{\circ} \mathrm{K}$ or $10.15 \%$ when compared to experimental data for the same 481 compounds.

Other estimation techniques, all for organic liquids, result in errors which are consistent with the proposed method. Johnson (1955) used 84 organic compounds at $20^{\circ} \mathrm{C}$ to develop a method which resulted in an average difference between experimental and estimated values of $6 \%$. Bondi's method (1966) resulted in an absolute difference of 610\%. Finally, Shaw's method (1969) developed group contributions for 63 groups and was applied to 120 organic liquids with an average absolute difference of $6.3 \mathrm{~J} / \mathrm{mole}^{\circ} \mathrm{K}$. Based on the preceeding methods, the large number of group contributions and the large number of compounds coupled with the low estimation error, the proposed estimation method for inorganic liquid heat capacities represents a significant improvement.

When 10 compounds not used in the regression for determining group contribution constants, the average absolute error is $5.47 \mathrm{~J} / \mathrm{mole}^{\circ} \mathrm{K}$, or $4.29 \%$ with a maximum difference of $15.135 \mathrm{~J} /$ mole $^{\circ} \mathrm{K}$ or $9.36 \%$. These results are consistent with the error found in the develop of the method. 
Table 1

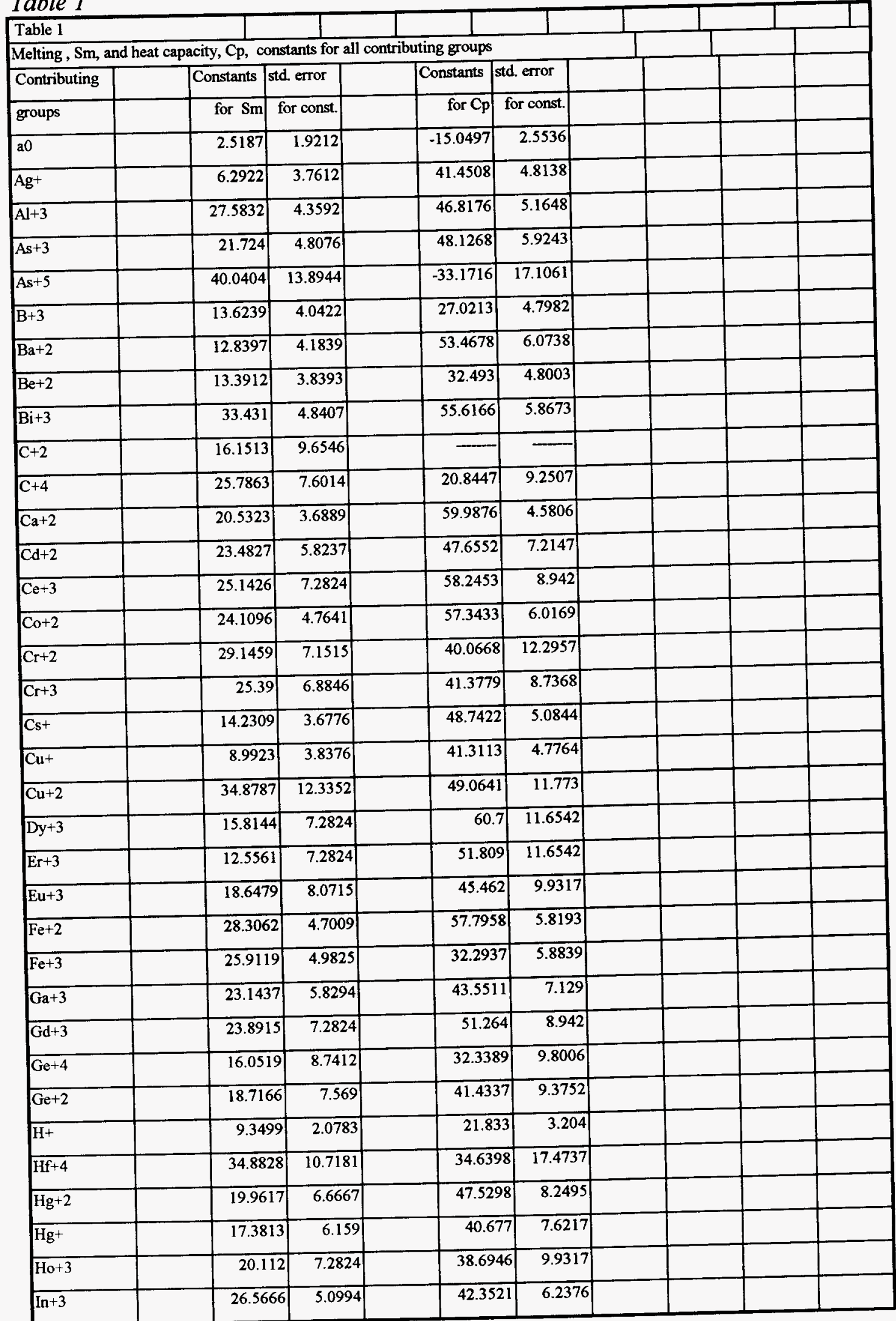




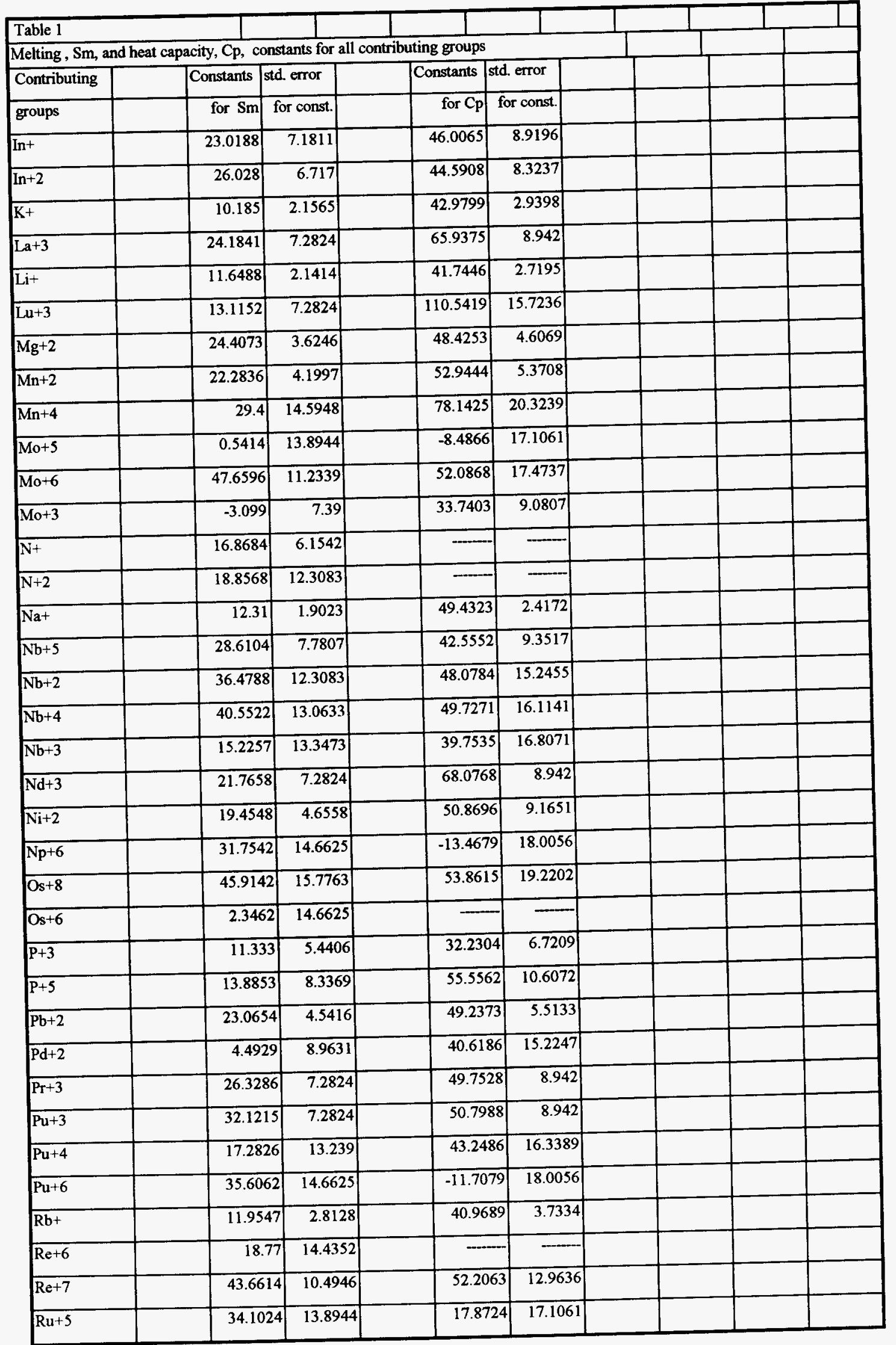




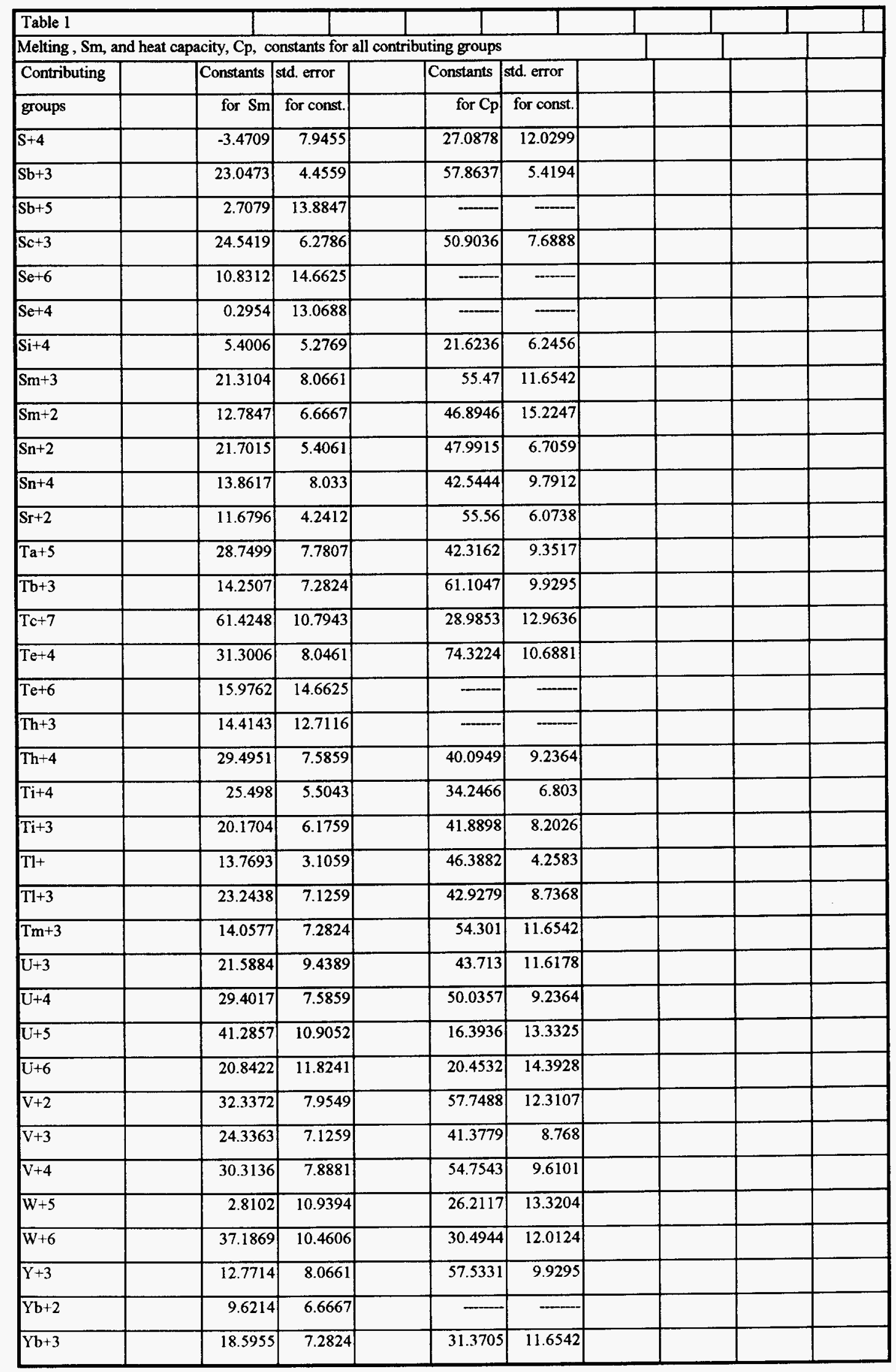




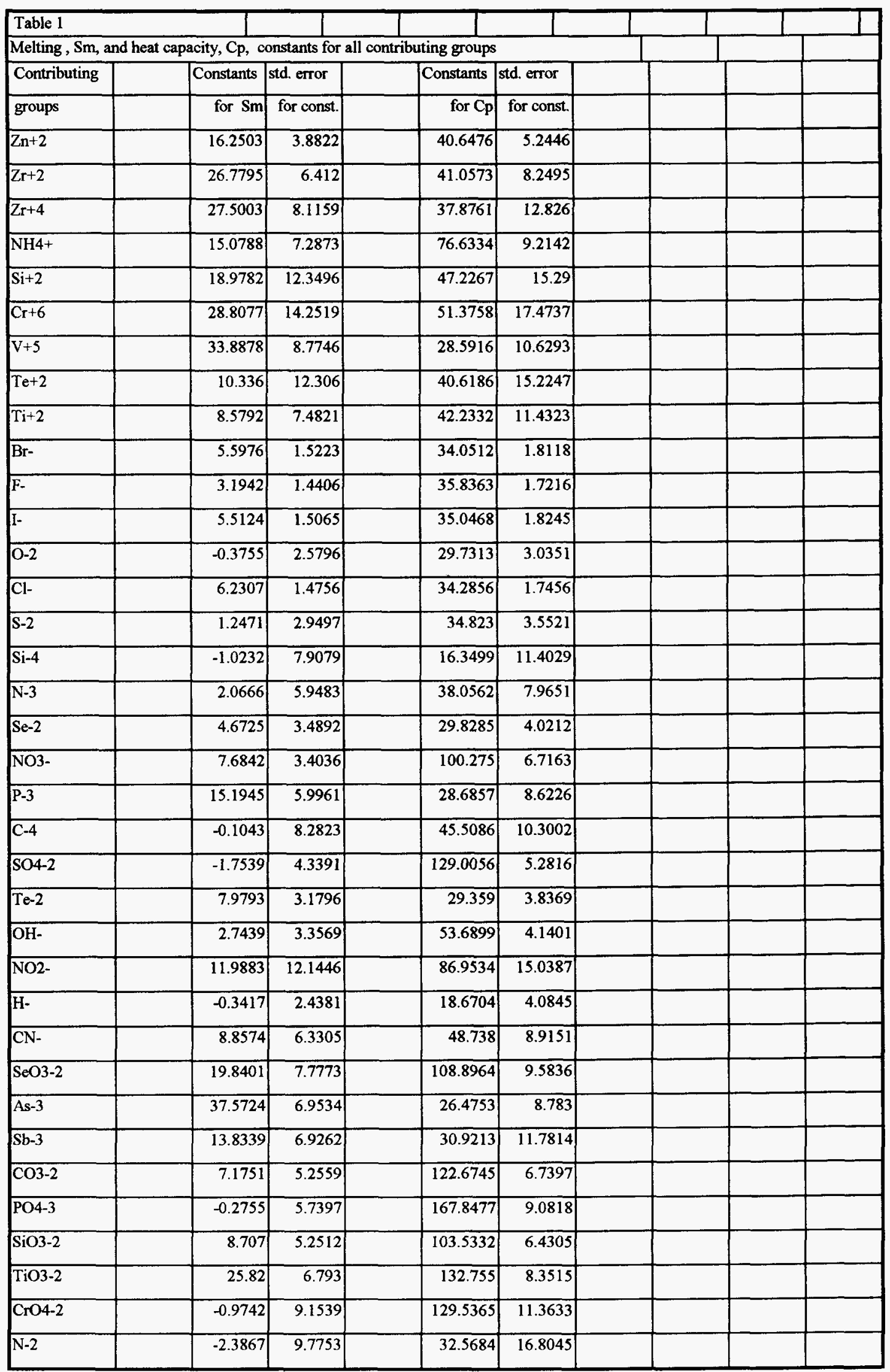




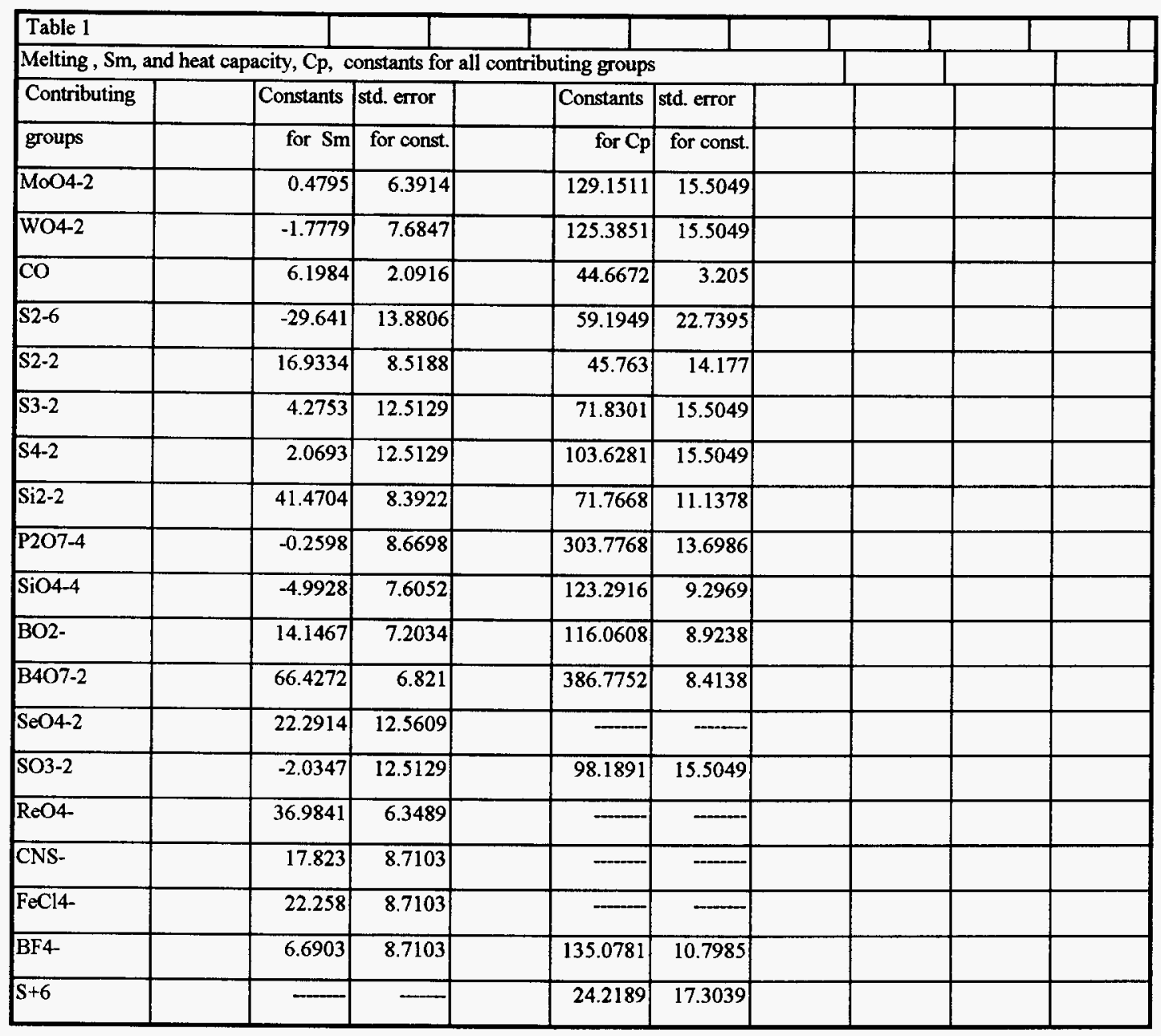




\section{Literature Cited}

Barin, I.; Knacke, O.; Kubaschewski, O.; Thermochemical Properties of Inorganic Substances, Supplement, Springer-Verlag, 1977.

Barin, I.; Thermochemical Data of Pure Substances, VCH, Germany, 1989.

Bondi, A.; A Correlation of the Entropy of Fusion of Molecular Crystals With Molecular Structure, Chem Rev. 1967, 67, 565.

Bondi, A., Estimation of the Heat Capacity, I\&EC Fundamentals, Vol. 5, No.4, 1966, 442.

Chickos, J.S.; Hesse, D.G.; Liebman, J.F.; Estimating Entropies and Enthalpies of Fusion of Hydrocarbons, J. Org. Chem., 1990, 55, 3833-3840.

Chickos, J.S.; Braton, C.M.; Hesse, D.G.; Liebman, J.F.; Estimating Entropies and Enthalpies of Fusion of Organic Compounds, J. Org. Chem., 1991, 56, 927-938.

Chickos, J.S.; Sternberg, M.J.E.; A Test of the Applicability of Small-Molecule Group Additivity Parameters in the Estimation of Fusion Entropies of Macromolecules, Thermochimica Acta, 1995, 264, 13.

Chow, W.M., Bright, J.A., Heat Capacities of Organic Liquids, Chem Eng. Progr. 49, 1953, 175.

Chueh, C.F., Swanson, A.C.; Estimating Liquid Heat Capacity, Chemical Engineering Progress, Vol. 69, No.7, 1973, 83.

Dannenfelser, R-M.; Yalkowsky, S.H.; Estimation of Entropy of Melting from Molecular Structure: A Non-Group Contribution Method, Ind. Eng. Chem. Res., 1996, 35, 14831486.

Dean, J. A. Lange's Handbook of Chemistry, McGraw-Hill Book Company, New York, 1979.

Denbigh, K.; The Principles of Chemical Equilibrium, Cambridge at the University Press, 1971, 201.

Dworkin, A.S., Bredig, M.A.; The Heats of Fusion and Transition of Alkaline Earth and Rare Earth Halides, J. Phys. Chem., 1963, 67, 697.

Felder R. M. and R. W. Rousseau, Elementary Principles of Chemical Processes, John Wiley and Sons, 1986, 365. 
Hirschfelder, J., Stevenson, D. Eyring, H., A Theory of Liquid Structure, J. of Chem. Phy., 1937, 5, 896.

Hunter, D. N., Inorganic Polymers, John Wiley and Sons Inc., New York, 1963.

Joback, K.G., Thesis. Massachusetts Institute of Technology, Cambridge, Massachusetts, June, 1984.

Johnson, A.I., Huang, C-J., Estimation of the Heat Capacities of Organic Liquids, Can. Jour. of Tech., 33, 1955, 421.

Knacke, O.; Kubaschewski, O.; Thermochemical Properties of Inorganic Substances, Springer-Verlag, 2nd Edition, Germany, 1990.

Lennard-Jones, J.E., Devonshire, A.F., Critical and Co-operative Phenomena: IV. A theory of disorder in solids and liquids and the process of melting; Pro. Roy. Soc.

(London), 1939, 170, 464.

Lumsden, J.; Thermodynamics of Molten Salt Mixtures; Academic Press, 1966.

Mostafa, A.T.M.G., Eakman, J.M., Montoya, M.M., Yarbro, S.L., Prediction of Heat Capacities of Solid Inorganic Salts from Group Contributions, I\&EC Research, 35, 1996, 343.

Mostafa, A.T.M.G., Prediction of Thermodynamic Properites of Inorganic Solids by the Method of Group Contributions, Ph.D. Dissertation, New Mexico State University, 1995.

Reid, R. C., Prausnitz, J. M.; Poling, . E.; The Properties of Gases and Liquids McGrawHill, Inc.; Fourth Edition, New Your, 1987.

Shaw, R., Heat Capacities of Liquids, Estimation of heat Capacity at Constant Pressure and $25^{\circ} \mathrm{C}$., Using Additivity Rules, Jour. of Chem \& Engr. Data, Vol. 14, No. 4, 1969, 461.

Thinh, T.P,. Trong, T.K., Estimation of Standard Heats of Formation, Standard Entropies of Formation, Standard Free Energies of Formation and Absolute Entropies of Hydrocarbons from Group Contributions. An Accurate Approach, Can. J. Chem. Eng. 1976, 54, 344.

Weast, R.C.; CRC Handbook of Chemistry and Physics, CRC Press; 54th Edition, Cleveland, Ohio, 1974.

Yoneda, Y., Bull. Chem Soc. Japan, 1979, 52, 1297. 
M98002653

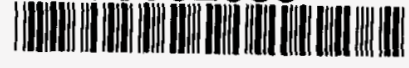

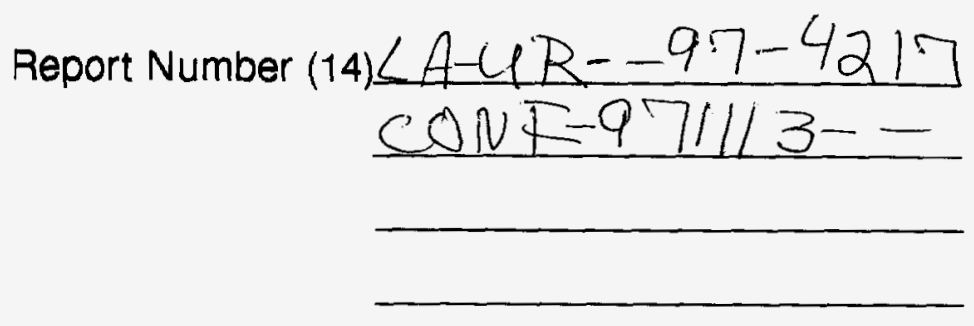

subl. Date (11) 19971117

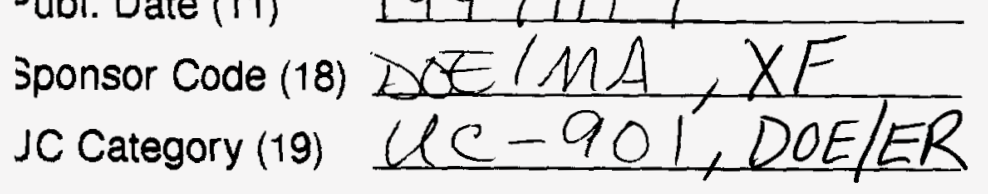

DOE 